\title{
Endoscopic biopsy of a B-cell lymphoma involving the entire ventricular system: A case report
}

\author{
JIA-ZHEN QIN $^{1,2^{*}}$, YUE-KUI WU ${ }^{1,2^{*}}$, ZHI-JUN YANG ${ }^{1,2}$, JUN LV $^{1,2}$, \\ YUAN-YUAN DANG ${ }^{1,2}$, HONG-TIAN ZHANG ${ }^{1,2}$ and YI-WU DAI ${ }^{1,2}$ \\ ${ }^{1}$ The Affiliated Bayi Brain Hospital, Military General Hospital of Beijing PLA; \\ ${ }^{2}$ Neurosurgical Institution of Beijing Military Region PLA, Beijing 100700, P.R. China
}

Received April 3, 2014; Accepted November 5, 2014

DOI: $10.3892 / \mathrm{etm} .2015 .2861$

\begin{abstract}
A 62-year-old male suffering from vomiting and mild preceding nausea for 15 days was examined in the present case report. Magnetic resonance imaging revealed a homogeneously enhancing cluster-like lesion involving the lateral, third and fourth ventricles. An endoscopic biopsy was performed, and histopathological examination led to the diagnosis of a high-grade diffuse large B-cell lymphoma. To the best of our knowledge, the present study reports the first case of a primary lymphoma involving the entire ventricular system. Therefore, primary lymphomas should be considered in the list of ventricular tumors. An endoscopic biopsy requires minimal invasion to obtain an adequate tissue sample, and frequently leads to the correct diagnosis and subsequent treatment protocols.
\end{abstract}

\section{Introduction}

Primary central nervous system lymphomas (PCNSLs) are a class of non-Hodgkin's lymphomas, which are primarily of diffuse large B-cell origin (90-95\%), with the remaining being T-cell lymphomas (5-10\%). The incidence of PCNSL has markedly increased over the last three decades (1). Primary ventricular lymphomas are extremely rare and may present as a solid mass or as diffuse ventriculitis. The clinical presentations of PCNSL are nonspecific and include headaches, vomiting, focal neurological deficits or global neurological deterioration (2). Since lymphomas are tumors

Correspondence to: Professor Hong-Tian Zhang or Professor Yi-Wu Dai, The Affiliated Bayi Brain Hospital, Military General Hospital of Beijing PLA, 5 Nanmencang, Dongcheng, Beijng 100700, P.R. China

E-mail: zhanghongtian007@126.com

E-mail: 601847608@qq.com

*Contributed equally

Key words: intraventricular tumor, fourth ventricle, B cell, high-grade with diffuse infiltration, surgical resection is not an efficient treatment; however, the disease may be controlled by chemotherapy and radiotherapy. Therefore, only a limited biopsy is required to confirm the diagnosis of a lymphoma, thereby preventing serious after-effects (1). Endoscopic neurosurgery for the biopsy of intraventricular brain tumors has been established in recent years. The efficacy of endoscopic tumor management is based on the principle that the intraventricular cerebrospinal fluid (CSF) serves as an excellent natural medium for imaging and light transmission. To date, only a few cases of intraventricular PCNSL have been reported in the literature (1-9). To the best of our knowledge, the present study reports the first case of PCNSL involving the entire ventricular system, as demonstrated by an endoscopic biopsy.

\section{Case report}

Written informed patient consent was obtained from the patient's family. In August 2012, a 62-year-old male was admitted to the Affiliated Bayi Brain Hospital of the Military General Hospital of Beijing PLA (Beijing, China), suffering from spontaneous, unrelenting vomiting and mild preceding nausea for 15 days, without the presence of a headache. The patient did not have previous medical history, general and neurological examinations were found to be normal and initial blood tests were unremarkable. A magnetic resonance imaging scan was performed, which revealed a homogeneously enhancing cluster-like lesion involving the lateral, third and fourth ventricles (Fig. 1A-C). To exclude the possibility of metastases, a whole-body positron emission tomography-computed tomography examination was performed, which produced negative results. No ventricular obstruction, other mass lesions or gross edemas were observed; therefore, the administration of steroids was withheld. An endoscopic biopsy was performed with neuronavigation under general anesthesia. The endoscopic biopsy revealed a white-red, solid mass with a rough surface on the occipital horn of the lateral, third and fourth ventricles, covering the foramen of Monro. Histopathological examination identified a highly cellular tumor comprising large cells with small decondensed nuclei and basophilic cytoplasm, scanty stroma and brisk mitotic activity, with the B-cell markers, CD20 and CD79a. In addition, $>80 \%$ of the cells exhibited 
Table I. Summary of primary fourth ventricular schwannoma

\begin{tabular}{|c|c|c|c|c|}
\hline Author/year & Age (yr)/Gender & Location & Clinical Signs & Treatment \\
\hline Werneck/1977 (5) & $17 / \mathrm{F}$ & 4th V & Meningitis & Not available \\
\hline \multirow[t]{2}{*}{ Bogdahn/1986 (9) } & $51 / \mathrm{M}$ & Lateral V & Seizures & Biopsy, chemotherapy, radiotherapy \\
\hline & $71 / \mathrm{F}$ & Lateral V & $\begin{array}{c}\text { Confusion, motor and speech disturbances, } \\
\text { left hemiparesis }\end{array}$ & Biopsy, chemotherapy, radiotherapy \\
\hline Haegelen/2001 (3) & $33 / \mathrm{F}$ & 4th V & $\begin{array}{l}\text { Headaches, vertigo, } \\
\text { static cerebellar syndrome }\end{array}$ & $\begin{array}{c}\text { Chemotherapy, stem cell transplantation, } \\
\text { radiotherapy }\end{array}$ \\
\hline Kelley/2005 (6) & $53 / \mathrm{M}$ & $3 \mathrm{rd} \mathrm{V}$ & Headache, seizures & Gross total resection \\
\hline Jung/2006 (7) & 63/M & $3 \mathrm{rd} \mathrm{V}$ & Confusion, left leg monoparesis & Radical resection \\
\hline Terasaki/2006 (8) & $56 / \mathrm{M}$ & Lateral V & Headache & Chemotherapy, radiotherapy \\
\hline Cecchi/2008 (2) & $71 / \mathrm{F}$ & 3rd V & $\begin{array}{c}\text { Confusion, motor speech disturbances, } \\
\text { left hemiparesis }\end{array}$ & Chemotherapy, radiotherapy \\
\hline Hill/2009 (4) & 69/M & 4th V & Vomiting, mild preceding nausea & Biopsy, chemotherapy \\
\hline Brar/2012 (1) & $65 / F$ & Lateral V, 4th V & Normal & Biopsy, chemotherapy \\
\hline Present/2014 & $62 / \mathrm{M}$ & $\begin{array}{l}\text { Lateral V, 3rd V, } \\
\text { 4th V }\end{array}$ & $\begin{array}{l}\text { Vomiting, with mild preceding nausea, } \\
\text { no headache }\end{array}$ & Biopsy, chemotherapy, radiotherapy \\
\hline
\end{tabular}

M, male; F, female; V, ventricle.

A

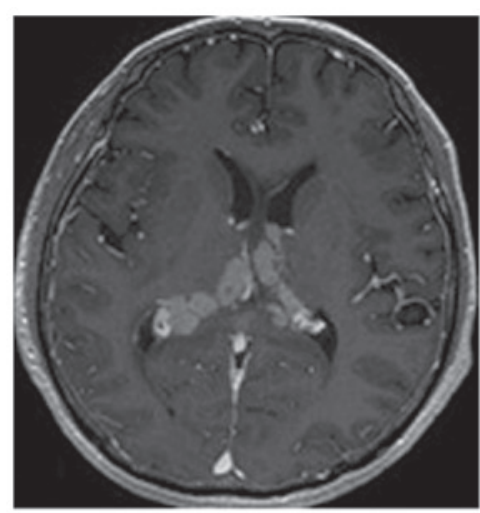

B

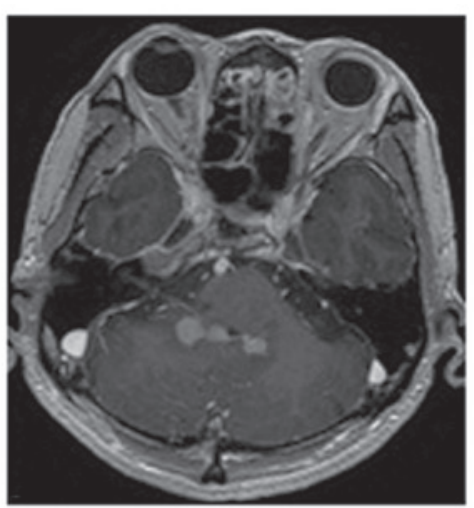

C

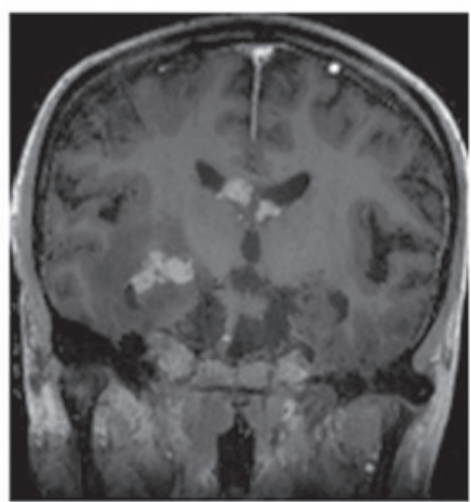

D

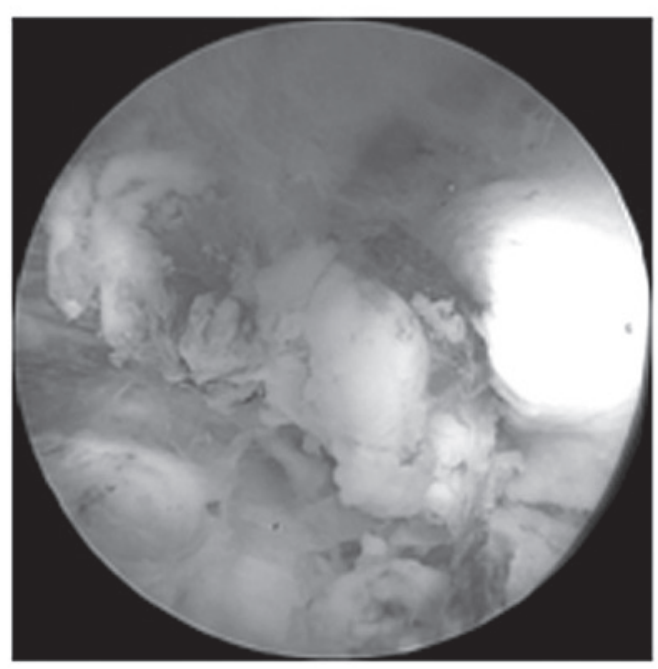

$\mathbf{E}$

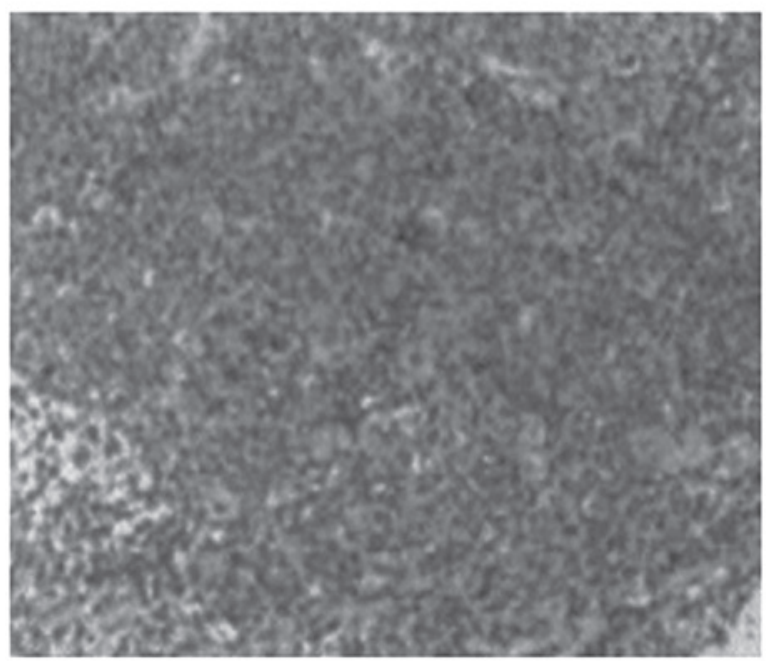

Figure 1. (A and B) Axial T1 and (C) coronal-weighted magnetic resonance imaging scans with gadolinium contrast agent, demonstrating the homogeneous enhancing activity of the tumor, which is located in the lateral, third and fourth ventricles. (D) An endoscopic biopsy revealed a white-red, solid mass with a rough surface, found on the occipital horn of the ventricles. (E) Histopathological examination confirmed the diagnosis of a high-grade diffuse large B-cell lymphoma.

nuclear positivity for the proliferation marker, Ki67, while the cells were found to be negative for Epstein-Barr virus latent membrane protein 1 . Thus, the patient was diagnosed with a high-grade diffuse large B-cell lymphoma. 
The patient commenced chemotherapy, which consisted of cyclophosphamide $\left(750 \mathrm{mg} / \mathrm{m}^{2}\right)$, doxorubicin $\left(50 \mathrm{mg} / \mathrm{m}^{2}\right)$ and vincristine $\left(1.4 \mathrm{mg} / \mathrm{m}^{2}\right)$, with a maximum single dose of $2 \mathrm{mg}$. The treatment was adminstered intravenously on day 1 , and etoposide was administered at a dose of $100 \mathrm{mg} / \mathrm{m}^{2}$ intravenously on days 1-3 alongside $100 \mathrm{mg}$ oral prednisone on days 1-5. This cycle was repeated every three weeks for six courses. The patient then underwent entire brain radiotherapy at a dose of $30 \mathrm{~Gy}$. The patient showed good recovery without any neurological deficits. Following the treatment, the levels of plasmatic markers (lactate dehydrogenase and $\beta_{2}$ microglobulin) were determined by protein electrophoresis, slit-lamp evaluation, a bone marrow biopsy and computed tomography scans of the chest and abdomen appeared to be normal. In addition, serological tests for human immunodeficiency virus, cytomegalovirus and Epstein-Barr virus were negative. At the seven-month follow-up examination, the patient was healthy, with no evidence of recurrence.

\section{Discussion}

Only a few cases of intraventricular PCNSL have been reported in the literature, of which three cases were in the fourth ventricle (2-5), four cases were in the third ventricle $(2,6,7)$ and three cases were in the lateral ventricles $(8,9)$, while only one case was identified with simultaneous involvement of the lateral and fourth ventricles (1). To the best of our knowledge, the present study reports the first case of a lesion involving the entire ventricular system. Table I shows the characteristics of the previously reported cases, along with the findings of the present study.

Although the occurrence of PCNSL is extremely rare, including the possibility of such tumor in the differential diagnosis of intraventricular neoplasms is required, particularly in cases where the lesion is located in one or multiple ventricles and exhibits a cluster-like appearance (10). Surgical resection is not an efficient treatment method for PCNSL; however, the disease may be controlled by chemotherapy and radiotherapy. Therefore, only a limited biopsy is required to confirm the diagnosis of a lymphoma, thereby preventing serious after-effects.

\section{References}

1. Brar R, Prasad A, Sharma T and Vermani N: Multifocal lateral and fourth ventricular B-cell primary CNS lymphoma. Clin Neurol Neurosurg 114: 281-283, 2012.

2. Cecchi PC, Billio A, Colombetti V, Rizzo P, Ricci UM and Schwarz A: Primary high-grade B-cell lymphoma of the choroid plexus. Clin Neurol Neurosurg 110: 75-79, 2008.

3. Haegelen C, Riffaud L, Bernard M and Morandi X: Primary isolated lymphoma of the fourth ventricle: case report. J Neurooncol 51: 129-131, 2001.

4. Hill CS, Khan AF, Bloom S, McCartney S and Choi D: A rare case of vomiting: fourth ventricular B-cell lymphoma. J Neurooncol 93: 261-262, 2009.

5. Werneck LC, Hatschbach Z, Mora AH and Novak EM: Meningitis caused by primary lymphoma of the central nervous system. Report of a case. Arq Neuropsiquiatr 35: 366-372, 1977 (In Portuguese).

6. Kelley TW, Prayson RA, Barnett GH, Stevens GH, Cook JR and His ED: Extranodal marginal zone B-cell lymphoma of mucosa-associated lymphoid tissue arising in the lateral ventricle. Leuk Lymphoma 46:1423-1427, 2005.

7. Jung TY, Jung S, Lee MC and Lee KH: Extranodal marginal zone B-cell lymphoma mimicking meningioma in lateral ventricle: a case report and possible pathogenesis. J Neurooncol 80: 63-67, 2006.

8. Terasaki M, Abe T, Tajima Y, Fukushima S, Hirohata M and Shigemori M: Primary choroid plexus T-cell lymphoma and multiple aneurysms in the CNS. Leuk Lymphoma 47:1680-1682, 2006.

9. Bogdahn U, Bogdahn S, Mertens HG, et al: Primary non-Hodgkin's lymphoma of the CNS. Acta Neurol Scand 73: 602-614, 1986.

10. Lettau $M$ and Laible $M$ : Primary intraventricular non-Hodgkin's lymphoma of the CNS. Rofo 184: 261-263, 2012 (In Chinese). 